\title{
Polymorphic DNA Markers in Black Cherry (Prunus serotina) Are Identified Using Sequences from Sweet Cherry, Peach, and Sour Cherry
}

\author{
Suzanne L. Downey ${ }^{1}$ and Amy F. Iezzoni ${ }^{2}$ \\ Department of Horticulture, Michigan State University, East Lansing, MI 48824
}

ADDitional INDEX wORDS. microsatellites, simple sequence repeats, chloroplast sequence

\begin{abstract}
Aвstract. Black cherry (Prunus serotina Ehrh.) is a common secondary forest species with a wide endemic distribution ranging from Nova Scotia south into Mexico, Ecuador, and Peru. Although planted in the United States for its valued lumber, black cherry is essentially a wild species with small fruit $\approx 6$ to $10 \mathrm{~mm}$ in diameter. In contrast, in Mexico and Ecuador, domesticates of this species called Capulin, have much larger ( 2 to $2.5 \mathrm{~cm}$ in diameter) edible fruit. To date, no studies of the genetic diversity within North American black cherry or the ancestral origin of the Capulin types have been conducted. Simple sequence repeats (SSRs, also termed microsatellites) would be the marker of choice for such genetic diversity studies due to their hypervariability; however, generation of these sequence-based markers is expensive. Therefore, our objective was to determine if markers already identified in other Prunus $L$. species would be informative in black cherry. The black cherry germplasm screened consisted of selections originating from Michigan, Mexico, and Ecuador. A chloroplast DNA marker, originally generated from sour cherry (P. cerasus L.), amplified three different sized products in black cherry. Four of the eight nuclear SSR markers tested from peach [P. persica L. Batsch (Peach Group)], sour cherry, and sweet cherry $(P$. avium $L_{\text {. }}$ ) also amplified and identified polymorphic markers. Together these four primer pairs resolved 54 putative alleles for the 66 black cherry accessions assayed. Success of the sweet cherry, peach, and sour cherry primers in identification of polymorphic markers in black cherry indicates it should be possible to use these markers for comprehensive molecular genetic studies in black cherry.
\end{abstract}

There are $\approx 400$ species within the genus Prunus; however, only 25 Prunus species are native to North America (Maynard et al., 1991). Among these 25 species endemic to the New World, only black cherry ( $P$. serotina) is grown in the United States for its high valued hardwood. Black cherry has a wide endemic distribution ranging from Nova Scotia, along the eastern United States coast, with populations extending into west Texas, southern Arizona, and New Mexico. This species is also endemic to central Mexico and into Ecuador and Peru (McVaugh, 1951).

In North America, black cherry is found commonly as a wild species in secondary forests (Maynard et al,. 1991), thriving in recently disturbed areas such as hedgerows and logging sites. The fruits of these North American types are small $(6$ to $10 \mathrm{~mm}$ in diameter), nonfleshy, astringent, and have no commercial value (McVaugh, 1951). In Mexico and into the Andean Highlands, however, domesticates of black cherry called Capulin have much larger edible fruit (average 2 to $3.5 \mathrm{~cm}$ in diameter) with large pits (Popenoe, 1924; Popenoe and Pachano, 1922). While the Capulin cherries are not cultivated in large numbers, they occur commonly in home gardens and along roadsides and fences (Downey, 1999). The fruit is often harvested and sold as fresh fruit in markets in Mexico and the Andean region. It is hypothesized that the large fruited Capulin resulted from domestication and selection by native peoples in Central America (Popenoe and Pachano, 1922).

Black cherry is a tetraploid $(2 \mathrm{n}=32)$ but it is not known if the species is an allotetraploid or autotetraploid and no progenitor species have been proposed. Geographic variation in black cherry

Received for publication 24 Mar. 1999. Accepted for publication 11 Oct. 1999 We thank Salvador Perez for enthusiastic assistance with germplasm collection in Mexico, Albert Abbott and Graham King for sharing their primer sequences, and James Hancock for helpful suggestions with this manuscript. The cost of publishing this paper was defrayed in part by the payment of page charges. Under postal regulations, this paper therefore must be hereby marked advertisement solely to indicate this fact.

${ }^{1}$ Graduate research assistant.

${ }^{2}$ Professor. has been studied using morphological characteristics (Carter et al., 1983); however, to date, no studies on the genetic diversity within North American black cherry or the ancestral origin of the Capulin types have been reported using molecular markers. The molecular markers of choice for genetic diversity studies are frequently simple sequence repeats (SSR, also termed microsatellites) (Litt and Ludy, 1989) due to their hypervariability, abundance, and relatively simple diagnostic polymerase chain reaction (PCR) procedure (Powell et al., 1996). SSR markers are a group of sequence tagged sites (STSs) where primers of specific sequence are designed to flank hypervariable regions of di-, tri- or tetra-nucleotide repeats (Litt and Ludy, 1989).

Widespread use of SSR markers is often hindered by the cost of identifying these markers since it involves library generation and sequencing. However, if primers designed to amplify loci in one species amplified loci in another species (termed heterologous amplification), the time and expense involved in isolating SSR markers for every species would be reduced. In Prunus, a limited number of SSR primer pairs are available from sweet cherry $(P$. avium) (C.D. Ryder, K. Edwards, and G.J. King, personal communication), sour cherry (P. cerasus) (A. Iezzoni, unpublished), and peach [P. persica (Peach Group)] (Gannavarapu, 1998).

The success of heterologous amplification using SSR primers depends generally upon the evolutionary distance between the original species and the tested species with decreasing success as genetic distance increases. In many mammalian species (Moore et al., 1991), bird species (Primmer et al. 1996), bovids and cervids (Engel et al., 1996), heterologous amplification has been quite successful. This is also the case in plant species with SSRs conserved frequently across related species and sometimes across genera. For example, cross-species amplification was prevalent among three mustard (Brassica L.) species (Szewc-McFadden et al., 1996) and among 10 Actinidia Lindl. species (Weising et al., 1996). Plant taxa where SSR primers amplified loci across genera in the same family include the Poaceae (Roder et al., 1995) and 
Citrinae subtribal group C (Kijas et al., 1995). In contrast, in the Asteraceae there was a lack of SSR conservation across the species tested (Whitton et al., 1997).

Genetic diversity and phylogenetic studies in plants frequently use chloroplast and nuclear markers due to their different modes of inheritance and rates of mutation. Chloroplast DNA (cpDNA) is inherited maternally in cherry (T. Brettin, personal communication) and is especially useful for phylogenetic studies due to its high degree of base sequence conservation (Curtis and Clegg, 1984; Palmer, 1987). Although cpDNA is conserved highly within aspecies, noncoding regions within the chloroplast genome have higher rates of mutation. Taberlet et al. (1991) identified PCR-based chloroplast polymorphisms by designing primer sets for conserved regions flanking noncoding variable regions of the chloroplast genome. When one of the primer sets, AB, designed by Taberlet et al. (1991), was used in sour cherry, seven length polymorphisms were identified(T. Brettin, personal communication). To better define the insertion/deletion events resulting in these seven polymorphisms, $\approx 300 \mathrm{bp}$ of sequence was obtained from each of the seven polymorphic 'AB' fragments (T. Brettin, personal communication). The first $300 \mathrm{bp}$ of sequence revealed two polymorphisms which differed for two insertion/ deletions. A primer pair spanning these two insertions/deletions was designed and termed the nested $\mathrm{AB}$ primers, $[\mathrm{AB}]$, to facilitate rapid screening of sour cherry germplasm for the length polymorphism. This nested cpDNA primer pair, [AB], was chosen as a chloroplast marker for use in this study.

The objective of this study was to examine the degree of conservation of a chloroplast marker derived from sour cherry and SSR loci developed from peach, sour cherry, and sweet cherry with a geographically diverse set of black cherry germplasm. For these PCR-based markers to be useful in genetic diversity and evolutionary studies in black cherry, they would not only need to exhibit heterologous amplification but also length polymorphisms/allelic diversity.

\section{Materials and Methods}

Black cherry seedlings were collected from Mexico, Ecuador, and Michigan (Table 1). Accessions from central Mexico were collected as open-pollinated half-sib seed from under Capulin trees in August 1996 and therefore represented five open-pollinated seed families (RG, PH, P2, P3, and T1). Two of these families (RG and T1) were collected by collaborators of S. Perez (Queretaro, Mexico). Ten Ecuadorian accessions were obtained from the Ecuadorian Germplasm Institute as open-pollinated seed presumably collected from five trees and were therefore termed five open-pollinated families [Ecu A 1-3, D 1-2, E 1, F 1-2, and H 1-2 (Raul Castillo, Departamento Nacional de Recursos Fitogeneticos y Biotecholigia, Quito, Ecuador)]. Ten black cherry plants were obtained as young seedlings from the Michigan State University (MSU) Department of Forestry, East Lansing. These seedlings originated from bulk seed of the black cherry collection at the Kellogg Biological Station, Hickory Corners, Mich. One black cherry accession currently growing on the MSU Campus (Beal) was also included.

One to 10 seedlings per family were scored for the chloroplast fragment and SSR loci (Table 1). DNA was extracted from young leaves following procedures of Stockinger et al. (1996). Amplification of the cpDNA fragment was done using two PCR reactions. The first PCR reaction used the 'AB' primers and amplification conditions described by Taberlet et al. (1991). The PCR product from this reaction was diluted 1:100 and used as template in a second PCR reaction with the $[\mathrm{AB}]$ nested primers (Table 2 ). The amplification products were separated on a $6 \%$ polyacrylamide gel run at $80 \mathrm{~V}$ for $2 \mathrm{~h}$ and stained using Silver Sequence staining system (Promega, Madison, Wis.). Amplified fragments were sized using a 10-bp ladder (Gibco BRL, Rockville, Md.).

Eight SSR primer pairs isolated from sour cherry, sweet cherry or peach were used. The sour cherry primers were obtained from a $P$. cerasus 'Erdi Botermo' genetic library (Iezzoni, unpublished). The sweet cherry and peach primers were obtained from G. King (Wellsbourne, United Kingdom) and A. Abbott (Clemson, S.C.), respectively. Optimization of PCR conditions for each primer pair was done using a temperature gradient PCR thermocycler (Robocycler) (Stratagene, La Jolla, Calif.). The products were separated and stained as described previously. Sequences and annealing temperatures for the successful primers are listed in Table 2.

Pairwise similarity values were calculated using the Nei-Li similarity index (Nei and Li, 1979) and the equation: $F=2 N_{x y} /\left(N_{x}\right.$

Table 1. Number of open-pollinated seedlings per family assayed for chloroplast DNA (cpDNA) polymorphisms and SSR markers. Number of individuals in each family exhibiting each cpDNA length polymorphism.

\begin{tabular}{|c|c|c|c|c|c|c|}
\hline \multirow{3}{*}{$\begin{array}{l}\text { Country } \\
\text { of origin }\end{array}$} & \multirow{3}{*}{$\begin{array}{l}\text { Family } \\
\text { designation }\end{array}$} & \multicolumn{2}{|c|}{$\begin{array}{l}\text { No. of seedlings } \\
\text { tested/family }\end{array}$} & \multirow{2}{*}{\multicolumn{3}{|c|}{$\begin{array}{l}\text { No. of seedlings } \\
\text { exhibiting the } \\
\text { cpDNA length } \\
\text { polymorphism }\end{array}$}} \\
\hline & & \multirow{2}{*}{$\begin{array}{l}\text { cpDNA } \\
\text { marker }\end{array}$} & \multirow{2}{*}{$\begin{array}{l}\text { SSR } \\
\text { loci }\end{array}$} & & & \\
\hline & & & & 250 & 274 & 280 \\
\hline \multirow[t]{5}{*}{ Mexico } & RG & 3 & 10 & 2 & & 1 \\
\hline & PH & 3 & 10 & & 3 & \\
\hline & $\mathrm{P} 2$ & 3 & 10 & & 3 & \\
\hline & P3 & 3 & 10 & & 3 & \\
\hline & $\mathrm{T} 1$ & 3 & 10 & & 3 & \\
\hline \multirow[t]{5}{*}{ Ecuador } & Ecu A & 1 & 3 & & 1 & \\
\hline & Ecu D & 1 & 2 & & & 1 \\
\hline & Ecu E & 1 & 1 & & 1 & \\
\hline & Ecu F & 1 & 2 & & 1 & \\
\hline & Ecu H & 1 & 2 & & 1 & \\
\hline \multirow[t]{2}{*}{ Michigan } & MI & 3 & 5 & & 3 & \\
\hline & Beal & 1 & 1 & & 1 & \\
\hline
\end{tabular}


Table 2. Summary of primer pairs derived from peach and sweet and sour cherry that identified size polymorphisms when tested on black cherry selections from Michigan, Mexico, and Ecuador.

\begin{tabular}{|c|c|c|c|c|c|c|c|}
\hline $\begin{array}{l}\text { Species } \\
\text { source }\end{array}$ & $\begin{array}{l}\text { Target } \\
\text { DNA }\end{array}$ & Primer & $\begin{array}{l}\text { Primer } \\
\text { sequence } \\
\left(5^{\prime}-3^{\prime}\right)\end{array}$ & $\begin{array}{l}\text { Annealing } \\
\text { temp } \\
\left({ }^{\circ} \mathrm{C}\right)\end{array}$ & $\begin{array}{l}\text { Expected } \\
\text { product } \\
\text { size }(\mathrm{bp})\end{array}$ & $\begin{array}{l}\text { Size range } \\
\text { of products } \\
\text { (bp) }\end{array}$ & $\begin{array}{c}\text { No. of size } \\
\text { polymorphisms/ } \\
\text { primer pair }\end{array}$ \\
\hline \multirow[t]{2}{*}{ Sour cherry } & Chloroplast & {$[\mathrm{AB}]$} & GCTGGAACCGTTGAATTCA & & & & \\
\hline & & & GGGGCATATCTAAGTATAA & 56 & 249 & $250-280$ & 3 \\
\hline \multirow[t]{2}{*}{ Sour cherry } & Nuclear & PceGA34 & GAACATGTGGTGTGCTGGTT & & & & \\
\hline & & & TCCACTAGGAGGTGCAAATG & 60 & 155 & $140-174$ & 14 \\
\hline \multirow[t]{2}{*}{ Sweet cherry } & Nuclear & PS12A02 & GCCACCAATGGTTCTTCC & & & & \\
\hline & & & AGCACCAGATGCACCTGA & 56 & 200 & $150-178$ & 12 \\
\hline \multirow[t]{2}{*}{ Peach } & Nuclear & pchpgms 3 & ACGCTATGTCCGTACCATCTCCATG & & & & \\
\hline & & & CAACCTGTGATTGCTCCTATTAAAC & 60 & 179 & $170-230$ & 19 \\
\hline \multirow[t]{2}{*}{ Peach } & Nuclear & pchgms2 & GTCAATGAGTTCAGTGTCTACACTC & & & & \\
\hline & & & AATCATAACATCATTCAGCCACTGC & 60 & 163 & $130-152$ & 9 \\
\hline
\end{tabular}

$+\mathrm{N}_{\mathrm{y}}$ ), where $\mathrm{N}_{\mathrm{x}}$ and $\mathrm{N}_{\mathrm{y}}$ are the total number of fragments identified in geographic groups $\mathrm{x}$ and $\mathrm{y}$, respectively, and $\mathrm{N}_{\mathrm{xy}}$ is the number of fragments shared by the two geographic groups.

\section{Results}

The nested chloroplast primers, $[\mathrm{AB}]$, amplified successfully a fragment in black cherry indicating that this region within the chloroplast genome is conserved between sour and black cherry. As expected, only one fragment was amplified in each reaction. Three different sized chloroplast fragments were identified: 250, 274, and 280. The most prevalent fragment, $274 \mathrm{bp}$, was present in all Michigan selections and four out of five Mexican and Ecuadorian selections (Table 1). In the Mexican RG family, two seedlings had a chloroplast fragment of $250 \mathrm{bp}$ while the third seedling had a 280 bp chloroplast fragment. One Ecuadorian accession, Ecu D, also exhibited the $280 \mathrm{bp}$ fragment.

Of the eight SSR primer sets tested, two primer sets failed to amplify fragments in black cherry. Both of these primer pairs were derived from peach. Two primer pairs, one derived from peach and one derived from sweet cherry, each amplified one monomorphic fragment from all the accessions and were therefore uninformative for genetic analyses.

The remaining four primer pairs tested amplified fragments that exhibited length polymorphisms among the accessions. These primer pairs were derived from sweet cherry (PS12A02), sour cherry (PceGA34), and peach (pchgms2 and pchgms3) (Table 2). Together, these four primer pairs resolved 54 putative alleles for the 66 black cherry selections assayed (Table 2).

The sour cherry derived primer pair PceGA34 amplified a total of 14 putative alleles ranging from 140 to $174 \mathrm{bp}$ in length (Table 2, Figs. 1A and 2). A maximum of two putative alleles were amplified per progeny sampled. Of the 14 putative alleles, one was specific to the Ecuadorian group, two were specific to the Mexican group, and two were specific to the Michigan group. One putative allele was present in all three geographical groups.

The sweet cherry primer pair PS12A02 was also highly informative, producing 12 putative alleles with a maximum of four putative alleles amplified per accession (Table 2, Fig. 1B). For this primer set, only four putative alleles were specific to any one particular geographical group: 164, 172, 176, and 178 bp were identified exclusively in Michigan selections. Only one putative allele was shared among all three geographical groups.

The peach primer pair pchgms 3 resolved the most putative alleles with 19 in total, ranging from 170 to $230 \mathrm{bp}$ in length (Table
2, Figs. 1C and 3). A maximum of four putative alleles were amplified for the selections assayed, representing the four alleles in the tetraploid black cherry. None of the putative alleles were specific to the Michigan or Ecuadorian groups. However, five putative alleles were only identified in the Mexican group (176, 196, 214, 226 , and $228 \mathrm{bp}$ ).

The peach derived primer set pchgms 2 amplified successfully nine putative alleles from all black cherry selections with a maximum of two putative alleles per sample (Table 2, Fig. 1D). One putative allele was uniquely identified in each of the geographical groups and no putative alleles were shared among all three geographical groups.

When all four heterologous primer pairs were considered separately, the data obtained from the black cherry selections were generally similar. For example, with all four primer pairs, no putative alleles were found to be shared exclusively between the Michigan and Ecuadorian selections (Fig. 1). Any putative alleles identified in both the Michigan and Ecuadorian selections were also always present within the Mexican selections. Additionally, with sour cherry, sweet cherry, and peach primers (PceGA34, PS12A02, and pchgms2, respectively), the selections from Equador were more similar to the Mexican selections than those from Michigan, and the selections from Ecuador and Michigan were the least similar (Table 3 ). The exception to this pattern is the peach primer pair pchgms3, where all 19 putative alleles were identified in the Mexican selections and no novel putative alleles were identified in the selections from Mexico and Michigan (Fig. 1).

\section{Discussion}

One chloroplast primer pair and four out of eight nuclear SSR primer pairs from sweet cherry, peach, and sour cherry exhibited heterologous amplification in black cherry and identified polymorphisms in the black cherry germplasm collection. These results suggest that DNA markers for use in genetic diversity and evolutionary studies in black cherry can be identified using some of the primers developed from peach, sweet cherry, and sour cherry.

The nested chloroplast primers $[\mathrm{AB}]$ designed from sour cherry sequence identified three different length fragments within the black cherry germplasm evaluated. Insertion and deletion events that give rise to length variants have been reported to account for a substantial fraction of intraspecific cpDNA variation (Zurawski and Clegg, 1987). Interestingly, two of the three fragments amplified in black cherry (274 and 250 bp) are similar in length to those identified in a French sweet cherry selection (276 bp) and in sweet, ground $(P$. 


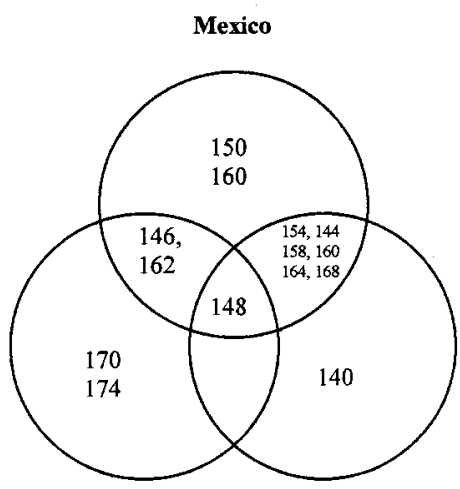

Michigan
Ecuador

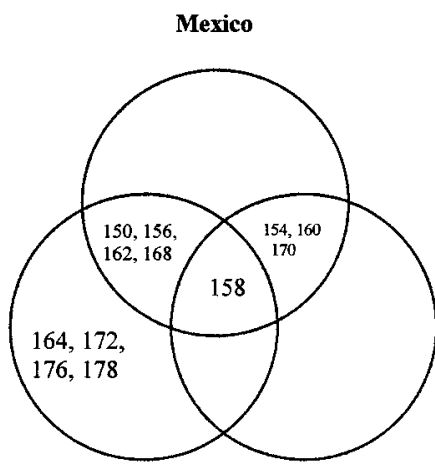

Michigan

Ecuador

\section{B}

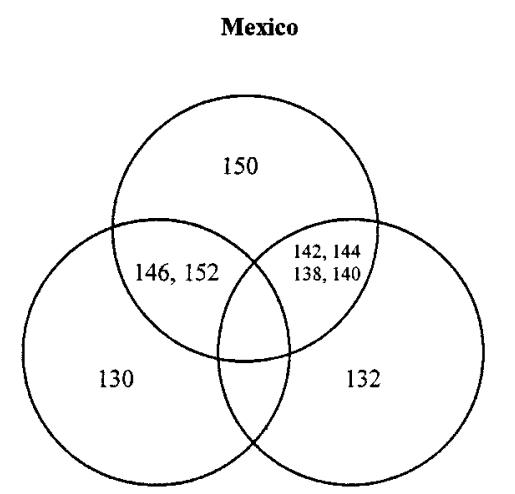

Michigan

D

Since cpDNA is inherited maternally in Prunus, it was expected that all the openpollinated seedlings from each family would have the same chloroplast fragment. However, seedlings from the Mexican family RG exhibited different fragments ( 250 and 280 bp). For the RG collection family, open pollinated seed collected by our collaborator was assumed to be derived from only one maternal parent tree. However, the cpDNA data suggest that multiple maternal parents were sampled for this family.

The 280-bp fragment exhibited by the Ecuadorian accession, Ecu D, may have resulted because Ecuadorian accessions were probably derived from multiple maternal parents as well. Morphologically, the RG and Ecu D families were indistinguishable from other collected families and subsequent assays with SSRs showed no further deviation of these accessions from the rest of the Capulin accessions. Therefore, cpDNA divergence is most likely due to collection of open pollinated seed from multiple maternal trees and not due to sampling of other Prunus species.

It is also theoretically possible that a somatic chloroplast length mutation could have arisen in the maternal plant and that this mutation could have resulted in open pollinated progeny with different chloroplast types (Hagemann, 1992). In the course of cell divisions, plastids segregate at random. This can result in somatic segregation and sorting out of genetically different plastids. Plant sectors that differ in their chloroplast type would then pass on different chloroplast types to their progeny. However, it is more likely that the chloroplast difference between progeny be-

Fig. 1. Putative alleles identified in black cherry selections from Mexico, Michigan, and Ecuador using the primer pairs (A) PceGA34, (B) PS12A02, (C) pchgms3, and (D) pchgms2. The numbers refer to the sizes of the fragments in base pairs.

fruticosa Pall.), and sour cherry selections (249 bp) (T. Brettin, personal communication). Amplification of the most prevalent 274 bp fragment in families from Michigan, Mexico, and Ecuador suggest that germplasm from these three regions share a common chloroplast type. However, since this primer pair also identified three chloroplast polymorphisms, it may be a useful marker for future analyses of the ancestral polyploid origin of black cherry. lieved to be from the same maternal parent is due to sampling from different maternal parents since it is a much simpler explanation.

The success in using heterologous PCR primers to amplify SSR loci in black cherry decreases the need to develop new sets of primers and therefore provides opportunities for population and evolutionary genetic studies in black cherry. Even within the Michigan black cherry germplasm, the four SSR primers derived from sweet and sour cherry and peach amplified 29 putative alleles

Fig. 2. Amplification products from primer pair PceGA34. Lane BP, 10-bp ladder; lanes 1 to 6, Michigan selections; lanes 7 to 17, Mexican black cherry selections; lanes 18 to 27, Ecuadorian black cherry selections.

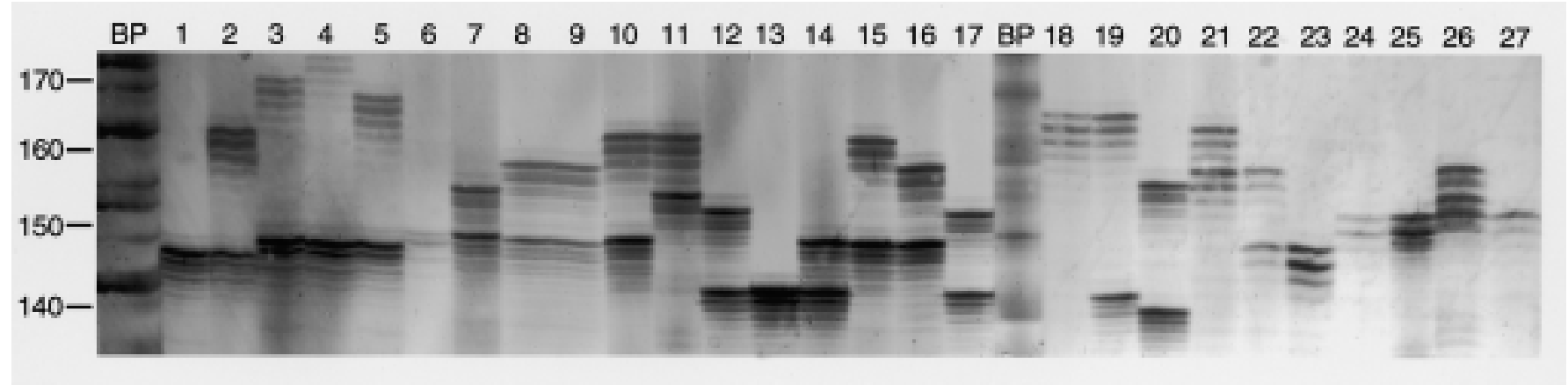




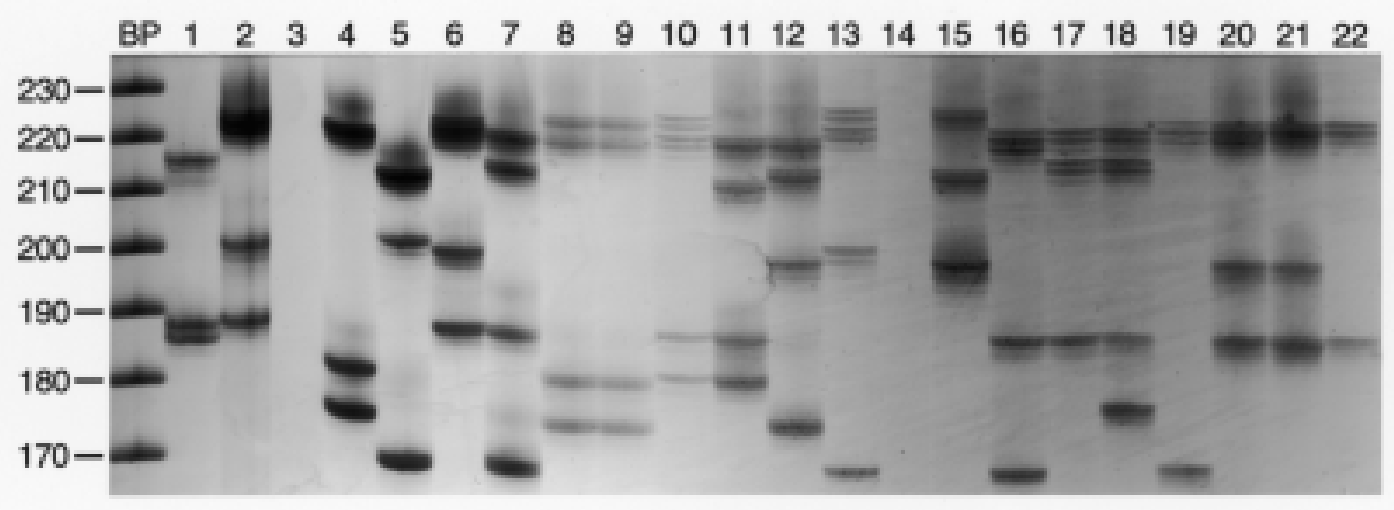

concerning the evolution of black cherry and the domestication of the Capulin types.

\section{Literature Cited}

Carter, K.K., F.C. Cech, and D.H DeHayes. 1983. Geographical variation in Prunus serotina. Can. J. Forest Res. 13:1025-1029.

Curtis S.E. and M.T. Clegg. 1984. Molecular evolution of chloroplast DNA sequences. Mol. Biol. Evol. 1:291-301.

Downey, S.L. 1999. Genetic diversity of Prunus serotina and the

Fig. 3. Amplification products from primer pair pchgms3. Lane BP, 10-bp ladder; lanes 1 to 12, Mexican black cherry selections; lanes 13 to 22, Ecuadorian black cherry selections.

Table 3. Similarity values (Nei and $\mathrm{Li}, 1979$ ) for pairwise comparisons of the black cherry selections from North America, Mexico, and Ecuador using four informative primer pairs.

Origin of selections

used in the

Primer pairs

\begin{tabular}{lcccc}
\cline { 2 - 5 } pairwise comparison & PceGA34 & PS12A02 & pchgms3 & pchgms2 \\
\hline Mexico and Equador & 0.74 & 0.66 & 0.64 & 0.66 \\
Mexico and Michigan & 0.38 & 0.59 & 0.77 & 0.40 \\
Ecuador and Michigan & 0.15 & 0.15 & 0.66 & 0 \\
\hline
\end{tabular}

suggesting that these SSRs could be used to conduct future population genetic studies within North American black cherry germplasm. Although only eight nuclear primer pairs were tested, the data suggest that within Prunus, the usefulness of a primer pair may depend more upon the primers themselves than the species origin of the primers. For example, the most useful primer pair was from peach, pchgms 3 . This primer pair amplified the maximum number of putative alleles compared to the other primer pairs tested and even identified tetra-allelic individuals. Identification of four putative alleles per progeny individual with one primer pair indicates that the primer sequences are conserved for all four alleles. In contrast, three other peach primer pairs tested either failed to amplify any bands or only amplified one monomorphic band. Of the two sweet cherry primer pairs tested, one amplified just one monomorphic band and the second amplified twelve putative alleles and the tetra-allelic individuals. It is possible that genetic distance and the usefulness of SSR primers may become more important when amplification is attempted across genera.

Results obtained from each of the four polymorphic primer pairs were similar. For example, the selections from Mexico exhibited the most putative alleles. With the exception of primer pair pchgms2, the Michigan selections had more putative alleles than the Ecuadorian selections. With the exception of peach primer pair pchgms3, selections from Mexico and Equador were more similar than selections from Mexico and Michigan, and the Equador and Michigan selections were the least similar. Also, with all four primer pairs no putative alleles were found to be shared by the Michigan and Ecuadorian selections that were not also present in the Mexican selections. This last observation suggests that the Ecuadorian and Michigan germplasm may have diverged from a central Mexican population presumably as a result of ecological adaptation and possibly domestication. These trends in the data identified by the four polymorphic primer pairs will be useful for testing hypotheses evaluation of other wild species for breeding sour cherry resistance to cherry leaf spot. MS thesis, Mich. State Univ., East Lansing.

Engel, S.R., R.A. Linn, J.F. Taylor, and S.K. Davis. 1996. Conservation of microsatellite loci across species of Artiodactyls: Implications for population studies. J. Mammalogy 77:504-518.

Gannavarapu, M. 1998 Microsatellite markers in peach [Prunus persica (L.) Batsch]: Abundance and utility. MS thesis, Clemson Univ., Clemson, S.C.

Hagemann, R. 1992. Plastid genetics in higher plants, p. 65-96. In: R.G. Herrmann (eds.). Plant gene research: Cell organelles. Springer-Verlag, New York.

Kijas, J.M.H., J.C.S. Fowler, and M.R. Thomas. 1995. An evaluation of sequence tagged microsatellite site markers for genetic analysis within Citrus and related species. Genome 38:349-355.

Litt, M. and J.A. Ludy. 1989. A hypervariable microsatellite revealed by in vitro amplification of a dinucleotide repeat within the cardiac muscle actin gene. Amer. J. Human Genet. 44:397-401.

Maynard, C.C., K. Havanagh, H. Fuernkranz, and A.P. Drew. 1991. Black cherry (P. serotina Ehrh.). Biotechnology in Agriculture and Forestry 16:3-22.

McVaugh, R. 1951. A revision of the North American black cherries. Brittonia 7:270-315.

Moore, S.S., L.L. Sargeant, T.J. King, J.S. Mattick, M. Georges, and D.J.S. Hetzel. 1991. The conservation of dinucleotide microsatellites among mammalian genomes allows the use of heterologous PCR primer pairs in closely related species. Genomics 10:654-660.

Nei, M. and W.-H. Li. 1979. Mathematical model for studying genetic variation in terms of restriction endonucleases. Proc. Natl. Acad. Sci. USA 76:52695273.

Palmer, J.D. 1987. Chloroplast DNA evolution and biosystematic uses of chloroplast DNA variation. Amer. Naturalist 130:S6-S29.

Popenoe, W. and A. Pachano. 1922. The capulin cherry. J. Hered. 13:50-62.

Popenoe, W. 1924. Hunting new fruits in Ecuador. Natural History 24:455-466.

Powell, W., G.C. Machray, and J. Provan. 1996. Polymorphism revealed by simple sequence repeats. Trends Plant Science 1:215-221.

Primmer, C.R., A.P. Moller, and H. Ellegren. 1996. A wide-range survey of crossspecies microsatellite amplification in birds. Mol. Ecol. 5:365-378.

Roder, M., J. Plaschke, W.U. Konig, A. Borner, M.E. Sorrels, S.D. Tanksley, and M. Ganal. 1995. Abundance, variability and chromosomal location of microsatellites in wheat. Mol. Gen. Genet. 246:327-333.

Stockinger E.J., C.A. Mulinix, C.M. Long, T.S. Brettin, and A.F. Iezzoni. 1996. A linkage map of sweet cherry based on RAPD analysis of a microspore-derived callus culture population. J. Hered. 87:214-218.

Szewc-McFadden A., S. Kresovich, S.M Bliek, S.E. Mitchell, and J.R. McFerson 1996. Identification of polymorphic, conserved simple sequence repeats (SSRs) in cultivated Brassica species. Theor. Appl. Genet. 93:534-538.

Taberlet, P.L. Gielly, G. Pautou, and J. Bouvet. 1991. Universal primers for amplification of three non-coding regions of chloroplast DNA. Plant Mol. Biol. 17:1105-1109.

Weising, K.R.,W.M. Fung, D.J. Keeling, R.G. Atkinson, and R.C. Gardner. 1996. Characterization of microsatellites from Actinidia chinensis. Mol. Breeding 2:117-131.

Whitton, J., L.H. Rieseberg, and M.C. Ungerer. 1997. Microsatellite loci are not conserved across the Asteraceae. Mol. Biol. Evolution 14:204-209.

Zurawski, G. and M.T. Clegg. 1987. Evolution of higher-plant chloroplast DNAencoded genes: Implications for structure-function and phylogenetic studies. Annu. Rev. Plant Physiol. 38:391-418. 